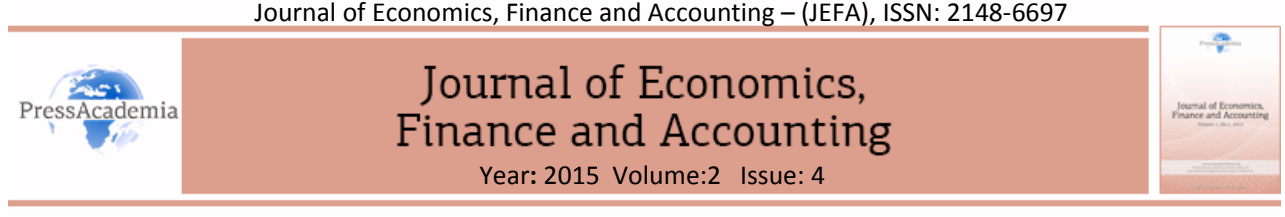

\title{
IOAIS: A NEW ACCOUNTING MODEL FOR KNOWLEDGE CREATION AND VALUE RECOGNITION
}

\author{
DOI: 10.17261/Pressacademia.2015414372
}

\author{
Ahmed Ali Mohammad ${ }^{1}$, Lina Hani Warad ${ }^{2}$ \\ ${ }^{1}$ Qatar University. amohammad@qu.edu.qa \\ ${ }^{2}$ Applied Science University of Jordan. L_warrad@asu.edu.jo
}

\section{Keywords}

Accounting, IOAIS, partnerships, knowledge creation, value contribution
JEL Classification

C41, M4, M49

\begin{abstract}
This paper adopts a holistic business approach to investigate the avaliability and value contributions of interorganizational accounting information systems (IOAIS). As prior researches have long been interested in investigating the operational contributions of AIS. This paper move a way from the operational contributions towards a more organic approach. The paper establishes a dynamic matrix with key value contribution parameters. Those parameters are: optimization of cost structure, quality improvment, growth of revenues, and customer satisfaction. The proposed matrix is demonostrated with practical analysis. An empirical survey using 19-item questionnaire has been used to acheive this objective. Qualitative and quantitative statistical methods are utilized to analyse the survey data. This paper contributes to business literature and has many practical implications. The survey results suggest key pillars for existance of IOAIS. Major outcomes of the analysis include that value contribution may vary according to IT infrastructure, information resources available, and organizational culture. The overall results show that IOAIS have value contributions measured according to factor ANOVA. Such results are expected to assist companies to better analyze and adapt AIS design to leverage its value and returns.
\end{abstract}

\section{INTRODUCTION}

As new technologies always emerging, business shifted, and companies alter their infrastructures, structures, forms, and information systems. The reason is that information technology provides the engine in which knowledge is created and exploited. IT as knowledge engine is playing such role through changing the business model, process nature, structures, and dynamics. Evidences show that companies who aggressively dominate the market through knowledge always have unique IT infrastructure and business process. A new class of IT infrastructure is incorporating business process via the Internet to both business and accounting systems (Sutton 2000). This accepted principle is very important introduction to the subject of this article. AIS have always been acting as a bridge (or engine) between business model and business process to achieve profitability objectives. This mechanism has been called the vertical approach in designing AIS. Interorganizational accounting system is integrated process based with strategic linkages and 
technological alliances. At the heart lie interorganizational process and strategic partnerships. Some companies for example have created a number of cross-functional processes that combine the functional knowledge to improve the flow of operations and customer services. The other companies have overlaid a horizontal process making partnerships to increase their market shares. Its involves re-architecting accounting information systems infrastructure interorganizationally, so that sharing, coordinating, and using business resources become almost instinctive and a part of performance. The rise of integrated business process has been key driver to the phenomenon of interorganizational information systems (Rom and Rohde 2007). Integrated business processes are based on minimizing operations and integrating external and internal customer's bases into these process, as well as the suppliers. This is to add value across the entire value chain (Sutton et. al 2008). The proposed alliance between accounting systems infrastructure and stakeholders communities provides the basis of what can be called horizontal or interorganizational accounting information systems. The impact of new business model has been extensive? Profitability can be seriously affected by a new style of inter-organizational business practices. The obvious question to be raised by this paper is what style of such impact on accounting information systems in terms of infrastructure, processes, and reporting forms. Inter-organizational accounting information systems are increasingly determined by its tremendous growth in interest since business processes have fashioned itself integrated and virtual. However; the mechanism of interest is apparently likely to be converted from being vertical to be horizontal. The impact of such conversion has planted the seeds of a new style of accounting systems and practices. Inter-organizational accounting information systems and their processes provide the accountants communities with new opportunities to measure and report business performance. Such measures track progress and performance horizontally across the business from one company to another. This paper is concerned with new nature of accounting information systems as an engine for third wave companies. The development of new areas like information technology, supply chain management, enterprise resource planning, business intelligence, e-commerce, etc. have further advanced the field of interorganizational accounting information systems. A new sort of accounting systems is not a luxury but a critical necessity for improving performance of knowledge based organizations. Contrary to the design of organizational accounting information systems, inter-organizational is multi-faceted; an inter-disciplinary infrastructure has considerable relevance for integrated business process. Special attention must be paid to restructuring, reconfiguring, and redesigning inter-organizational accounting information systems. Research in this area has to be of many dimensions depending on the new nature and unique purpose of inter-organizational practices. Accordingly, this paper examines whether evidence can be found for the idea that inter-organizational infrastructure and collaboration supports the effectiveness of innovation strategies. The question which this paper tries to answer is that IOAIS has succeeded to developing a critical mass of knowledge and capabilities that will help accountant's community to cope with future challenges? The reminder of this paper is organized as follows: Section II is the core one and explores the structural components of inter-organizational accounting information systems in comparison with accounting information systems. Section III reviews relevant literatures that develop concepts and process of interorganizational information systems. Section IV introduces a discussion of the methodology and data source used in the 
analysis. Section $\mathrm{V}$ discusses the results of the statistical analysis of research variables. Finally, section VI draws some conclusions from the analysis process of this paper.

\section{THEORITICAL FRAMEWORK}

Inter information systems have been an important research topic and much of the research projects have shown that integration was the trigger point behind the interorganizational phenomenon. Nicolaou (2000) and Yeunyong (2007) stated that there is cause relationship between use of integrated systems and the emergence of IOIS. Technically, interorganizational information systems is based on use of integrated business process which is more dynamic and require continuous adjustment and realignment as technology and market opportunities evolve (Larsen and Klischewski 2004). Inter-organizational information systems can be viewed as nexus of architecture, infrastructure, processes, rules, and practices that have taken new forms and many relations between and within different organizations. A new infrastructure makes a balance between intra and inter uses of information systems because business knowledge and value is created when integrations are made between the isolated organizational information systems (Rodon et al 2006). The secret of success for inter-organizational information systems lies at the point of intersection of technology adoption, process orientation, stakeholders interaction, and value creation (See Table-1). Taking into consideration the relationships inherent in these components, inter-organizational information systems demands more vision and innovation because it is comprehensive and multi-dimensional. In contrary, traditional inter information systems research assumes a value chain perspective through integration of information systems. According to business literature, use of interorganizational information systems is considered an imperative engine for successful supply chain and knowledge management. The reasons have been associated with tangible improvements and profitability (Barua et. al 2004; Boone and Ganeshan, 2007). Further, interorganizational collaboration has been recognized as important in supplementing the internal innovative activities of organization (Deeds and Rothaermel, 2003; Faemset et. al 2005; Dodgson 1993; Hagedoorn, 2002. The emergence of knowledge business model has transformed much of traditional information systems on its head (Smith et al. 2008). In the field of inter-organizational accounting information systems, the concept of interorganizational accounting has been developed initially from academic work of Otley et al. 1995 and Hopwood 1996. Interorganizational information systems have been radically transformed the nature and style of accounting practices (Hunton, 2002). The traditional accounting model has been invented to match the needs of autonomous business model. Changing business model to be shared, integrated and dynamic entails consistent change in accounting model (Hopwood 1996). IOAIS has not drawn a lot of attention especially in terms of how these systems can be restructured to match necessities of new business model. New business model and success is driven by the technological partnerships and strategic alliances with stakeholders (Mouritsen et al. 2001). Adopting these technological partnerships and alliances necessitates a new accounting information system and model. The problem of intra systems of accounting is that flow of information in all these systems and models are vertical. In contrast, the flow of information in inter business systems are horizontal. Further, the dramatic shift of knowledge economy from competition to collaboration has made IOAIS increasingly blurred and the arguments therefore are growing strongly. 
Accepting the above new realities and their implications do not match existing rules, practices, and traditions of organizational accounting information systems. This fact has created the debate about paradigm of information versus value in designing accounting information system (Christensen and Demski 2003). The debate is centered on the idea that accounting systems have to be designed to communicate information or measure value (Scapens and Varoutsa 2010). According to information perspective, accounting systems should be designed to provide information and viewing financial measures as measures of information events. In contrast, according to value perspective, the accounting systems should be designed to measure value. Coad and Cullen 2006 adopted what they term evolutionary thinking to explore the emergence of inter-organizational accounting information systems. These systems are likely to have quite different rules and policies to accounting for inter-organizational relationships (Seal et al. 2004). This is one of the reasons that knowledge as opposed to the information demands a very dynamic system to match collaboration and knowledge creation. As a result, inter-organizational accounting information systems have been shifted the focus from reporting generated profit to how such profit can be generated and improved by appropriate applied knowledge practices (Mohammad 2014). This is exactly the problem of new systems of accounting which is constructed by strategically mixing a variety of information resources (Christensen and Demski 2004). According to the most business thinkers, traditional practices of accounting information systems is a poor guide to inter-organizational and future business adventures because it's give few clues to the changes in key processes and capabilities that determines the business strength. Recent researchers have found that the traditional ideology of accounting is now being seriously questioned? Unless accounting information system is realigned with current move toward integrated business process, the accountant's community must not be surprised when their systems are shaped back into the second wave. IOAIS procedures, methods, rules, and measures must be developed to link the interorganizational practices with recording and reporting process of accounting and the way to disclose these practices in financial statements. Table-1 below depicts reliable comparison for IOAIS versus OAIS in terms of nature, procedures, rules, and objectives. 
Table 1: IOAIS VS OAIS

\begin{tabular}{|c|c|c|}
\hline Dimension & IOAIS & OAIS \\
\hline Nature & $\begin{array}{ll}\checkmark & \text { Knowledge System. } \\
\checkmark & \text { Horizontal. } \\
\checkmark & \text { Financial and non-financial. } \\
\checkmark & \text { Relationships } \\
\checkmark & \text { Inter. } \\
\checkmark & \text { Integrated, cross-disciplinary, ad } \\
& \text { hoc, fluid, and collaborative. } \\
\checkmark & \text { Success in expanding relationships. }\end{array}$ & $\begin{array}{ll}\checkmark & \text { Information System } \\
\checkmark & \text { Vertical } \\
\checkmark & \text { Financial } \\
\checkmark & \text { Visible and physical activities. } \\
\checkmark & \text { Intra. } \\
\checkmark & \text { None integrated, closed, restricted, } \\
& \text { and has boundaries of single } \\
& \text { businesses. } \\
\checkmark & \text { Success in control. }\end{array}$ \\
\hline Procedures & $\begin{array}{ll}\checkmark & \text { Invisible flow of knowledge. } \\
\checkmark & \text { Value Creation. } \\
\checkmark & \text { Flexible, collaborative, and } \\
& \text { dynamic. } \\
\checkmark & \text { Strategic. } \\
\checkmark & \text { Comprehensive. } \\
\checkmark & \text { Technical } \\
\checkmark & \text { Centered on knowledge. }\end{array}$ & $\begin{array}{ll}\checkmark & \text { Physical flow of resources } \\
\checkmark & \text { Value Realization. } \\
\checkmark & \text { Rigid, isolated, and static. } \\
\checkmark & \text { Operational. } \\
\checkmark & \text { Financial. } \\
\checkmark & \text { Procedural } \\
\checkmark & \text { Centered on data }\end{array}$ \\
\hline Rules & $\begin{array}{ll}\checkmark & \text { Focused on technology process. } \\
\checkmark & \text { Supporting collaboration with } \\
& \text { business partners. } \\
\checkmark & \text { Networking. } \\
\checkmark & \text { Extracted from e-business model. } \\
\checkmark & \text { Reporting value. }\end{array}$ & $\begin{array}{ll}\checkmark & \text { Focused on accounting process. } \\
\checkmark & \text { Supporting performance of } \\
& \text { recording and reporting process. } \\
\checkmark & \text { Blocking } \\
\checkmark & \text { Extracted from t-business model. } \\
\checkmark & \text { Reporting cost. }\end{array}$ \\
\hline Objectives & $\begin{array}{ll}\checkmark & \text { Creating and sharing knowledge } \\
\checkmark & \text { Value proposition matrix: balancing } \\
\text { performance, behavior, and } \\
\text { technology. } \\
\checkmark & \text { Reporting Dynamic: Instant and } \\
\text { online. }\end{array}$ & $\begin{array}{ll}\checkmark & \text { Measuring profitability. } \\
\checkmark & \text { Value proposition matrix: cost, } \\
& \text { time, and quality. } \\
\checkmark & \text { Reporting Dynamic: Periodical. }\end{array}$ \\
\hline
\end{tabular}

\section{RESEARCH AGENDA}

Accounting and IT have become inseparable. In contrary to conventional wisdom of accounting information systems, IOAIS are playing central role in the coordination and development of knowledge creation. The field of inter-organizational accounting information systems is still full of controversy associated with how such systems have to be architected and required infrastructure to be designed. Technically, contribution to knowledge creation and innovation is an important opportunity still exists to develop terms and terminology of inter-organizational accounting information systems. The current model yields several propositions that suggest the dynamic nature of new style of accounting systems. A key proposition is that it may their collaboration facilitate knowledge creation and innovation. In developing a comprehensive research methodology for current paper, past research on common aspects of interorganizational systems have been used as basis for defining the current research framework. These 
research aspects are integrated infrastructure, collaboration, partnerships, knowledge creation, and internal innovative activities. All of these aspects (or variables) were drawn from literature on IOIS, which suggested by various researchers (Chatterjee and Ravichandran 2006, Faems et al 2005, Khuong 2012, Melin and Axelsson 2013, Mueller et al 2013, Sutanto et al 2009, Rodon 2006, Reimers et al 2008, Han et al 2004, Leung et al 2012).

This paper adopts cross-companies and quantitative research designs to address the above formulated research aspects. Data were obtained by collecting direct and indirect documentation. The designed questionnaire has been structured and developed to reflect critical issues in architecting and designing inter-organizational accounting information systems. The scope of integration is interface and networked. The guiding semi-structured questions focused on the following critical issues that were targeted on formulating research model: (i) the general infrastructure; (ii) integration and collaboration; (iii) knowledge creation and innovation; and (iv) impacts of contribution of interorganizational accounting information systems (See Figure-1). The survey results were tabulated and analyzed by use of SPSS. Statistically, this research is using factor ANOVA computations. The preference for using factor ANOVA is the classification of data and the assumption that such method makes use of the entire data set. However, the use of ANOVA is preferred for the factorial design underlying such method. According to most business literature, factorial design is specifically useful in simultaneous analysis in addition to investigating how different levels of independent variables affect the dependent variable. Another advantage of factorial design is that allow greater generalizability of the results. Finally, the survey has been tested with Asian companies of a size sufficient to have interorganizational technologies. Those companies are belonging to different business industries. The lack of literature and the limited empirical evidence on issues of IOAIS have created the need to conduct preliminary research interviews with managers in sampled companies. Therefore, exploratory interviews were used to facilitate the research process and survey design. 
Figure 1: Research Model

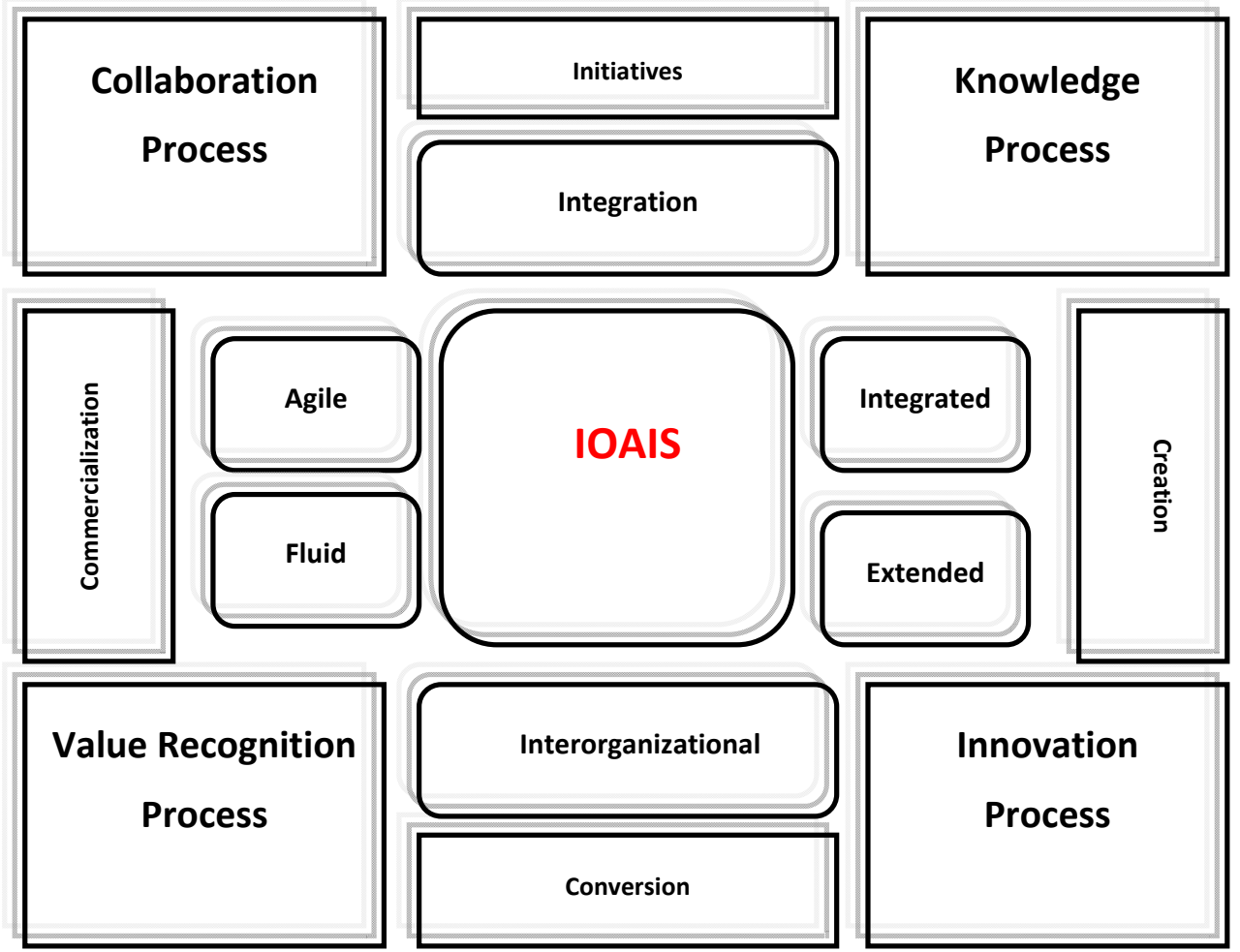

\section{METHOD OF SURVEY \& DATA ANALYSIS TECHNIQUE}

This paper used primary data that was collected from a sample of different industries. The sampled companies selected based on two main criteria. Those are style of interorganizational technologies and type of integrated business process. The sample surveyed sixteen manufacturing companies. A structured questionnaire consisting of closed ended questions was developed based on above critical issues of inter-organizational accounting information systems. Questions on the perceived impacts-give a statement and ask for the level of impact on scale ranging from 1 (company survive), 2 (cost reduction), 3 (quality improvement), 4 (customer satisfaction), 5 (customer retention). The first group designed to gather information on demographic profile of the respondents. The other groups from the second to fifth structured according to four parameters explored in review of literature. To refine and validate questions asked and prior to managing the survey, the first version of the questionnaire has been validated through expert interviews and a panel of academics and practitioners. Further, the first version was tested by using the results from three respondents. According to feedback from the pilot test, the final draft of the questionnaire revised by removing those questions with low reliability and modifying those lacking semantic clarity. A total of 16 questionnaires has been distributed to the targeted sampled companies. In the sample of companies replying to the 
questionnaires \% 38 were food manufacturing, \% 19 paper manufacturing, \% 12 pharmaceutical, \% 6 electrical, \% 12 chemical, \% 6 petroleum, and \% 6 tobacco manufacturing. Analysis of the results by automation shows that $\% 18$ were partially automated and \% 82 fully automated. Questionnaires have been distributed to staff members who were in charge of finance and technology functions. The qualitative data gathered through in-depth individual interviews and focus groups. Interviews have been carefully managed with financial managers of the sampled companies. Specifically, the criteria for choosing companies were:

- Integration of business processes whether fully or partially.

- Partnerships with business partners.

- Use of inter-organizational technologies to create knowledge.

- Value contribution for IOAIS.

To analyse the survey data, qualitative and quantitative statistical methods are utilized. At first, data have been checked, recorded, cleaned, and aggregated to a firm level. Completed questionnaires have further checked for missing values and inconsistencies in response given by the respondents. Qualitative analysis has been managed were appropriate. The questions in the questionnaire have been analysed in tabular form using simple percentage, mean values, standard deviation, and t-test. These statistical techniques have been divided into two stages. In the first stage, the descriptive statistics have been analyzed to investigate the parameters and to establish the mandatory requirements to design inter-organizational accounting information systems. In the second stage, the value contribution of IOAIS have been examined. In the statistical analysis, in order to delve more deeply into the results the survey data have been segmented into four groups according to variables of research model (See Figure-2). In the following section of the research an ANOVA analysis was made to investigate the existence of the four design requirements among research samples and examine the results.

\section{EMPIRICAL FINDINGS}

\subsection{IOAIS DESIGN REQUIREMENTS}

The first stage in the statistical analysis has been focused on the way to proof the availability of inter-organizational accounting information systems. The critical success factors which formulated according to the developed models in business literature have been used as drivers to manage INOVA modeling techniques to test both infrastructure and relationships models. Table-1 presents the descriptive statistics for quality of IOAIS design requirements. The researcher used \% change in infrastructure as the independent variable to measure \% change in critical success factors as the dependent variables of interest. According to available data, the customer process were most affected by sophisticated infrastructure of inter-organizational accounting information systems with percentage of impact equal to 95.4 and 60.3. These results support the hypothesis that inter-organizational infrastructure has increased package of services introduced by of accounting information systems and then customer's satisfaction and retention. The significance results for partnerships were as reflected in Table-1. The impact of infrastructure on other critical success factors still need to be more investigated. The 
results revealed that partnerships had less positive impact on critical success factors with score of 43.4, 14.6, 9.7, 7.4, and 4.8 respectively (See Table-2). This result could be attributable to nature of sampled companies and business environment. Statistic confirm that low values indicate the need for more explanatory variables to be investigated. The scored results for collaboration were so significant at 10 percent levels of significance.

Table 2: Summary of IOAIS Design Requirements

\begin{tabular}{|c|c|c|c|c|}
\hline & $\begin{array}{l}\overleftarrow{\Xi} \\
\stackrel{\Xi}{\Xi}\end{array}$ & $\begin{array}{l}\text { Sums of } \\
\text { Squares }\end{array}$ & $d f$ & $\begin{array}{c}\text { Mean } \\
\text { Square }\end{array}$ \\
\hline & 1 & 10.726 & 6 & 1.787 \\
\hline & 2 & 7.611 & 6 & 1.268 \\
\hline \multirow[t]{5}{*}{ Infrastructure } & 3 & 14.726 & 6 & 2.454 \\
\hline & 4 & 5.389 & 6 & .898 \\
\hline & 5 & 3.676 & 6 & .612 \\
\hline & 1 & 11.075 & 7 & 1.582 \\
\hline & 2 & 8.007 & 7 & 1.143 \\
\hline \multirow[t]{5}{*}{ Partnership } & 3 & 19.267 & 7 & 2.752 \\
\hline & 4 & 8.646 & 7 & 1.235 \\
\hline & 5 & 5.171 & 7 & .738 \\
\hline & 1 & 14.130 & 8 & 1.766 \\
\hline & 2 & 11.885 & 8 & 1.485 \\
\hline \multirow[t]{5}{*}{ Integration and Collaboration } & 3 & 27.247 & 8 & 3.405 \\
\hline & 4 & 15.084 & 8 & 1.885 \\
\hline & 5 & 10.383 & 8 & 1.297 \\
\hline & 1 & 14.130 & 8 & 1.766 \\
\hline & 2 & 11.885 & 8 & 1.485 \\
\hline \multirow[t]{3}{*}{ Knowledge and Innovation } & 3 & 27.247 & 8 & 3.405 \\
\hline & 4 & 15.084 & 8 & 1.885 \\
\hline & 5 & 10.383 & 8 & 1.297 \\
\hline
\end{tabular}

Table 3: Summary of Significance Test

\begin{tabular}{|l|c|}
\hline & $\mathrm{F}$ \\
\hline Infrastructure & .004 \\
\hline Partnership & 2.715 \\
\hline Integration and Collaboration & .000 \\
\hline Knowledge and Innovation & .839 \\
\hline
\end{tabular}




\subsection{VALUE CONTRIBUTION OF IOAIS}

The second stage of the statistical analysis has been focused on value proposition of IOAIS. To verify assertions of current research, T-test were conducted to analyze the overall impact while mean, standard deviation, and percentage of overall impact to analyze the detailed impact. The results of the questionnaire responses are shown in Table 3 . The respondents are generally in agreement with the idea that IOAIS have value creation impact. The mean score of all parameters were above 3 and standard deviations do not deviate significantly from the means. The results show that high $t$-value where equal to $(t=5.275, p<0.05)$ and the minimum $t$-value being equal to $(t=2.087, p>0.05)$. The results reported in Table 3 reveal that mean for this parameter was equal to (5.04). However, the statistically significant calculated t-value (5.275) compared with tabulated t-value (3) indicates that the respondents agree that highest value creation impact generated by reducing cost. Further analysis of the statistical significance indicates that level of cost reduction tends to vary across sampled companies (Table 3 ). High mean of cost reduction scored in process of inter-organizational accounting information systems (6.33) compared with lowest mean of (3.67) across organizational accounting information systems. The percentage of such impact ranged from (\% 57.1) to (\% 90.4) with variance of (.707). This high score of results can be attributed to new style of business process, procedures, and invisible flow of information instead of the costly physical flows. One interesting finding is the large contribution of cost reduction through most of inter-organizational accounting information systems because of integration of business processes weather fully or partially. In regard to quality improvement, the results show that the respondents ranking quality improvements as part of value creation impact of inter-organizational accounting information systems with mean equal to (4.79). The testing of t-value indicates that calculated was equal to (4.683) comparing with tabulated (3). Examining the perceived impact of quality improvements associated with inter-organizational accounting processes shows that quality have more improved as a result of using of inter-organizational technologies with mean equal to (6.50). The percentage of such impact approximated (\% 61.9 - \% 92.9) associated with variance equal to (1.069). This result is probably explained by the way processes of quality control is implemented and managed. Standardization of quality control processes has streamlined and accelerated those processes and then easing its automation and integration. Integration of business processes as a result of use of inter-organizational technologies have generated value creation impact through what can be called completeness and new nature of quality control processes. The results of the questionnaire responses demonstrated that the present scenario of inter-organizational technologies has not that much impacted growth of revenues (See Table-3). The impact of these technologies has been modest and most likely preliminary. Thus, mean of the survey response related to this parameter was equal to (4.28). The low impact is also evident in testing t-value as the calculated cited by (2.087) which is lower than the tabulated that was equal to (3). Examination of the statistical data shows that the variance rates associated with this parameter were higher than other. Accounting information systems were the least organizational information systems affected by use of innovative technologies in terms of maximizing revenues with mean equal to (3.11) associated with variance equal to (2.315) and total percentage of impact ranged between (\% 54 - \% 73). There is however a high degree of consensus among respondents that creative uses of 
inter-organizational technologies of AIS to maximize revenues in surveyed companies still needed. Results in Table 3 have indicated high and significant impact exists between use of inter-organizational technologies of AIS and customer satisfaction. The results of the survey shows mean equal to (4.79) and spectrum of impacts ranged from (\% 55.6) to (\% 92.9). The parameter had statistically significant $t$ value with calculated $t$ equal to (4.719) compared with tabulated $t$ equal to (3). This result indicates that use of interorganizational technologies of AIS has value creation impact that related to customer base and satisfaction. However, the inter-organizational impacts associated with this parameter has shown that improvement in quality control systems generated customer satisfaction with mean (6.50) and total impact equal to (\% 92.9) associated with variance equal to (1.069). The lowest impact that related to customer satisfaction was cited by billing management systems with mean equal to (3.89) and total impact equal to (\% 55.6) associated with variance equal to (2.421). Respondents have viewed integration of sale process associated with killing time and cost as a driver beyond such rate of customer satisfaction. Looking closely at surveyed inter-organizational technologies of AIS provides a clear picture that it has a lot of potential especially in the area of customer management and sales orders. Table 3 details scores of value creation impact for inter-organizational technologies of AIS.

Table 4: Mean Scores and One Sample t-test Statistics

\begin{tabular}{|c|c|c|c|c|c|c|c|}
\hline Value Parameter & Mean & $\begin{array}{c}\text { Average of Overall } \\
\text { Impact }\end{array}$ & Calculated t. & Tabulated $t$. & $d f$ & Sig. & dif. \\
\hline $\begin{array}{l}\text { Optimization of Cost } \\
\text { Structure }\end{array}$ & 5.04 & $\begin{array}{c}(\% 73.65) \\
(\% 57.1-\% 90.4)\end{array}$ & 5.275 & 3 & 8 & .001 & 2.1433 \\
\hline Quality Improvement & 4.79 & $\begin{array}{c}(\% 73.1) \\
(\% 61.9-\% 92.9)\end{array}$ & 4.683 & 3 & 8 & .002 & 2.0744 \\
\hline Growth of Revenues & 4.28 & $\begin{array}{c}(\% 64.48) \\
(\% 54-\% 73)\end{array}$ & 2.087 & 3 & 8 & .070 & 1.2840 \\
\hline $\begin{array}{l}\text { Satisfaction of } \\
\text { Customer }\end{array}$ & 4.79 & $\begin{array}{c}(\% 73.8) \\
(\% 55.6-92.9)\end{array}$ & 4.719 & 3 & 8 & .002 & 1.7919 \\
\hline
\end{tabular}

\section{CONCLUSIONS}

This paper has considered inter-organizational accounting information system which is truly multi-disciplinary and inter-disciplinary. In general, the practical impression has shown that there is a relationship between use of integrated technologies and availability of IOAIS. This paper attempted to develop a structural model about inter-organizational accounting information systems, focusing on concepts, processes, and new role as knowledge driver. In the implications of the empirical survey, different variables and dimensions have been defined to match the requirements of factor ANOVA analysis. Statistically, evaluation of the relationships and positive outcomes of the results could provide preliminary indications support existence and dynamic role of inter-organizational accounting information systems.

The current paper has introduced clear understanding for superiority and significant value contribution impact of inter-organizational accounting information systems. This paper contributes to IOAIS literature and has many practical implications. The value contribution 
impact of IOAIS related to business process was varied across these process in terms of rate and applications. The empirical results are in support of findings of other IOIS researches. The value contribution impact ranged from medium to high, and future research is needed to further investigate the relationship between IOAIS and earning power of business. The key result which the current paper has indicated is that the value contribution impact for IOAIS entails realistic adaptation for inter-organizational technologies to match business needs. For future researches, additional data are needed to assess the innovative and value contribution effect of IOAIS. Data needed are related to type of IT infrastructure, availability of business resources, and style of business culture.

Accountant's community has been slow to evolve the research program to tackle the transformation in the field of inter-organizational accounting information systems. It needs to re-examine their knowledge and skills in coping with new demanding role of their systems as knowledge driver. The role played by accounting has been transformed with the development of new accounting information systems. A new role expedites the process of accounting to create knowledge and growth. The introduction of interorganizational accounting information systems has necessitated the redefinition of accounting. The most important contribution of this paper is to draw a new orientation of accounting. This new orientation entails using new technologies, systems, and process to capture knowledge that could turn into greater return on investment. The accountant's community needs to consider the idea of complementing traditional accounting practices toward exploitation of advantages of interorganizational business model. Accounting for customers, supply chains, horizontal or open book are titles for this new orientation. These findings help accounting community to intensify their initiatives to encourage greater understanding and acceptance for inter-organizational accounting information systems.

\section{REFERENCES}

Barua, A.; Konana, P.; Whinston, A. B., and Yin, F. (2004) An Empirical Investigation of Net Enabled Business Value, MIS Quarterly, Vol. 28, No. 4, pp: 585-620.

Boone, T. and Ganeshan, R. (2007) the Frontiers of e Business Technology and Supply Chains, Journal of Operations Management, Vol. 25, No. 6, pp: 1195-1198.

Chatterjee, Dipanjan and Ravichandran, T. (2004) Inter-organizational Information Systems Research: A Critical Review and an Integrative Framework, Proceedings of the $37^{\text {th }}$ Hawaii International Conference on System Science, 2004, pp: 1-10.

Chirstensen, John and Demski, Joel S. (2004) Asymmetric Monitoring: Good versus Bad News Verification, Schmalenbach Business Review, Vol. 56, July 2004, pp: 206-222.

Cho, Vincent (2007) A Study of the Impact of Organizational Learning on Information Systems Effectiveness, Int. J. of Business and Information, Volume 2, No. 1, 2007, pp: 127-158.

Coad, A. F. and Cullen, J. (2006) Inter-organizational Cost Management: Towards an Evolutionary Perspective, Management Accounting Research, Vol. 17, pp: 342-369.

Corbiere, Francois de (2008) Interorganizational Information Systems and Data Quality Improvement: The Case of Product Information in the French Large Retail Industry, Research Paper.

Faems, Dries; Looy, Bart Van; and Debackere, Koenraad (2005) Interorganizational Collaboration and Innovation: Toward a Portfolio Approach, the Journal of Product Innovation Management, Vol. 22, pp: 238-250. 
Georgel, Tudor Catalin and Vasile, Florescu (2009) Extended Enterprise and Information Systems Governance in an Inter-organizational Context, Annals of Faculty of Economics, 2009 Vol. 4, Issue 1, pp: 1070-1075.

Granlund, Markus (2009) On the Interface between Accounting and Information Systems, Sarja/Series A-13: 2009, pp: 1-72.

Hald, Kin Sundtoft (2005) Managing Inter-organizational Relationships-Using the Force of Partner Attraction, Working Paper No. 01/2005, pp: 1-28.

Han, Kunsoo; Kauffman, Robert J.; and Nault, Barrie R. (2004) Information Exploitation and Interorganizational Systems Ownership, Proceedings of the Thirty-Seventh Hawaii International Conference on System Sciences (HICSS-37), PP: 1-42.

Hopwood, A. G. (1996) Looking across rather than up and down: On the need to explore the lateral processing of information; Accounting, Organization, and Society Vol. 21, pp: 589-590.

Hunton, J. E. (2002) Blending Information and Communication Technology with Accounting Research, Accounting Horizons, Vol. 16, No. 1, pp: 55-67.

Larsen, Michael Holm and Klischewski R. (2004) Process Ownership Challenges: IT Enabled Transformation of Interorganizational Business Process, Proceedings of the $37^{\text {th }}$ Annual Hawaii International, pp: 1-11.

Leung, Nelson K. Y.; Lau, Sim Kim; and Tsang, Nicole (2012) An Ontology-Based Collaborative Interorganizational Knowledge Management Network (Cik-Net), PACIS 2012 Proceedings, Paper 38, 113.http://aisel.aisnet.org/pacis2012/38.

Mohammad, Ahmed Ali (2014) "Value Propositions Matrix of ERP Technologies: The Transition from Transactional to Value Creation Engine", International Journal of Applied Information Systems, Vol. 7, No. 10, October 2014, pp: 21-27.

Mouritsen, J.; Hansen, A.; and Hansen, C. O. (2001) Inter-organizational Control and Organizational Competencies: Episodes around Target Cost Management/Functional Analysis and Open Book Accounting, Management Accounting Research, Vol. 12, pp: 221-244.

Nicolaou A. I. (2000) "A Contingency Model of Perceived Effectiveness in Accounting Information Systems: Organizational Coordination and Control Effects", International Journal of Accounting Information Systems, Vol. 1 (2000), pp: 91-105.

Khuong, Mai Ngoc (2012) The Factors Affecting Inter-Organizational Relationship Success: A Study of Vietnamese Travel Companies and Thai Partners, NIDA Development Journal, Vo. 52, No. 2/2012, pp: 1-33.

Melin, Ulf and Axelsson, Karin (2013) Inter-organizational Interaction in Public and Private Sectors: Comparative Study, Transforming Government: People, Process, and Policy Vol. 7, No. 4, pp: $431-452$. http://dx.doi.org/10.1108/TG-07-2013-0018.

Mueller, Tobias; Schuldt, Denis; Sewald, Birgit; Morisse, Marcel; and Petrikina, Jurate (2013) Towards Interorganizational Enterprise Architecture Management: Applicability of TOGAF 9.1 for Network Organizations, Proceedings of the Nineteenth Americas Conference on Information Systems, Chicago, Illinois, August 15-17, 2013, pp: 1-13.

Reimers, Kai; Johnston, Robert; and Klein (2008) A Theorizing Evolution of Inter-organizational Information Systems on Long Timescales, Proceedings of JAIS Theory Development Workshop, Sprouts: Working Paper on Information Systems, 8(31), http://sprouts.aisnet.org/8-31.

Rodon, Juan, Esade (2006) A Methodological and Conceptual Review of Inter-organizational Information Systems Integration, ECIS 2006 Proceedings. Paper 206. http://aisel.aisnet.org/ecis2006/206.

Rom, Anders and Rohde, Carsten (2007) "Management Accounting and Integrated Information Systems: A literature review", International Journal of Accounting Information Systems, Vol. 8 (2007), pp: 40-68.

Scapens, Robert W. and Varoutsa, Evangeia (2010) Accounting in Networks: Accounting in Inter-organizational Relationships, New York: Routledge, U.S.A., pp: 314-341.

Seal, W.; Berry, A.; and Cullen, J. (2004) Disembedding the Supply Chain: Institutionalized Reflexivity and Interfirm Accounting; Accounting, Organization, and Society, Vol. 29, pp: 73-92. 
Smith, Stephen P.; Rahim, Md Mahbubur; Shanks, Graeme; and Johnston, Robert B. (2008) How Organization Goals Affect Interorganization System Implementation Projects: Evidences and Implications, Asia Pacific Management Review, Vol. 13, No.3, 2008, pp: 675-581.

Sutton, Steve G. (2000) "The Changing Face of Accounting in an Information Technology Dominated World", International Journal of Accounting Information Systems, Vol. 1 (2000), pp: 1-8.

Sutton, Steve G.; Smedley, Georgia; and Arnold, Vick (2008) Accounting for Collaborative Supply Chain Relationships: Issues and Strategies, The International Journal of Digital Accounting Research, Vol. 8, No. 14, pp: $1-22$.

Yeunyong, W. (2007) "Causes and Consequences of AIS Effectiveness in Manufacturing Firms: Evidence from Thailand", International Journal of Business Research, Nov. 7, Issue 6. 